\title{
One-Stage Urethroplasty for Strictures in Maiduguri, North Eastern Nigeria
}

\author{
Ahmed Gadam Ibrahim, Nuhu Ali, Sulieman Aliyu, and Abubakar Alhaji Bakari \\ Department of Surgery, College of Medical Sciences, University of Maiduguri and University of Maiduguri Teaching Hospital, \\ P.M.B., Borno State, Maiduguri 1414, Nigeria
}

Correspondence should be addressed to Nuhu Ali, nuhualinvwa@yahoo.com

Received 4 November 2011; Accepted 15 December 2011

Academic Editors: G. Nabi, R. Shiri, and F. M. Wagenlehner

Copyright ( 12012 Ahmed Gadam Ibrahim et al. This is an open access article distributed under the Creative Commons Attribution License, which permits unrestricted use, distribution, and reproduction in any medium, provided the original work is properly cited.

\begin{abstract}
Background. Urethral stricture is a frequent cause of lower urinary tract obstruction worldwide. The aim of this study is to present our experience with one-stage urethroplasty. Methods. All males that underwent one-stage urethroplasty between January 2001 and December 2010 were retrospectively reviewed. Details of their biodata, clinical presentation, diagnostic investigations, operative treatment, postoperative complications, and other outcome of surgery were extracted and analyzed. Results. Ninety-one patients aged $8-76$ years, (mean; $45.6 \pm 19.7$ ) with urethral stricture were studied. Postinfective strictures accounted for $58.2 \%$ and postprostatectomy strictures for 3.3\%. Twenty-six (27.9\%) of the strictures were in the posterior urethra of which $18(59.2 \%)$ were posttraumatic. Fifty-seven strictures $(61.3 \%)$ were in the anterior urethra of which $51(54.8 \%)$ were postinfective. Thirtynine (42.9\%) patients had end to end anastomosis, 29 (31.9\%) flap augmentation and $17(18.7 \%)$ tabularized flap substitution, and $6(6.6 \%)$ dorsal onlay grafts ( 5 with buccal mucosa and 1 with penile skin). There were 18 (19.8\%) cases of wound infection, $12(13.2 \%)$ of restricture and $6(6.6 \%)$ cases of urethrocutaneous fistula. Satisfactory urinary stream was found in 77 (84.6\%) patients. There was no mortality. Conclusion. Infection is the commonest cause of urethral stricture followed by trauma, and one-stage urethroplasty give excellent results.
\end{abstract}

\section{Introduction}

A urethral stricture is caused by narrowing of the urethral lumen due to spongiofibrosis, resulting in loss of distensibility and compliance, leading to poor urinary stream which may lead to further complications. It is a common problem worldwide affecting mainly the male urethra [1]. The aetiology of acquired urethral strictures varies from inflammatory causes to traumatic scarring after blunt perineal/pelvic trauma and iatrogenic causes following surgery or urethral catheter use $[2,3]$.

Most postinfective strictures are located in the anterior urethra (bulbopenile), whereas posttraumatic strictures affect the bulb or cause posterior urethral disruption or distraction the latter is a serious challenge to the urologist, because they are often associated with significant complications including incontinence and erectile dysfunction [4].

Various forms of repair of the urethra have been developed and perfected over the years, ranging from excision and end-to-end anastomosis in short segment strictures to substitution urethroplasty in long segment strictures. The aim is to produce a wider, stable, and more compliant or distensible urethra that will produce a positive impact on voiding $[5,6]$.

We undertook one-stage approach because, in the interval between the first and second stages, infections of the operating site are common, making the second stage of the operation more difficult; furthermore, most of our patients are of the low socioeconomic status and can afford surgery only once in their life time. We managed 91 patients by onestage urethroplasty at the UMTH over a 10-year period; this retrospective study details the outcome of our intervention.

\section{Patients and Methods}

All males that underwent one-stage urethroplasty for urethral stricture at the UMTH between January 2001 and 
December 2010 were retrospectively reviewed. Details of their biodata, clinical presentation, diagnostic investigations, operative treatment, postoperative complications, and other outcome of surgery were extracted from their hospital records and analyzed. The diagnosis of urethral stricture was made on clinical assessment, a retrograde urethrogram (RUG) and micturating cystourethrogram (MCUG). The patients had initial urinary diversion by a suprapubic cystostomy (SPC). One-stage urethroplasty was performed on all patients after resuscitation where necessary, ensuring optimal renal function and treating any urinary tract infection with antibiotics based on sensitivity. Penile skin flap, substitution, or augmentation urethroplasty were the main surgical techniques used. With a few buccal mucosal on-lay grafts, short segment strictures, and those from posterior urethral disruption, had end-to-end anastomosis after excision of the stricture, while long segment or beaded postinflammatory strictures were repaired by penile skin flaps. Calculi, bladder diverticuli, abdominal wall hernias were treated at the same surgery or after the urethroplasty have healed. The postoperative outcome was carefully documented. Thirteen patients with incomplete medical records were excluded from the study.

\section{Results}

A total of 91 patients had one-stage urethroplasty during the study period. Their mean age was $45.6 \pm 19.67$ years (range $8-76)$. The 41-50-year-age group was the most affected accounting for $20(21.9 \%)$ patients (Table 1$)$. The causes of urethral stricture are outlined in Table 2 which included post-infective in $53(58.2 \%)$, post-traumatic in $30(32.9 \%)$, iatrogenic, as a complication of urethral catheterization in 5 $(5.5 \%)$ and as a complications of prostatectomy in $3(3.3 \%)$ patients. Sixty-seven $(72 \%)$ strictures were in the anterior urethra comprising 26 (38.8\%) bulbar, 34 (50.7\%) bulbopenile, and $7(10.4 \%)$ penile. Twenty-six $(28.0 \%)$ of the strictures were in the posterior urethra Table 3. Most of the patients presented with progressive poor urinary stream that improved with straining. Eleven (12.1\%) presented in acute urinary retention, while $6(6.6 \%)$, presented with multiple perineal urinary fistulae (watering can perineum). The mean duration of symptoms was 24 months for the postinflammatory strictures, and 3-6 months for the posttraumatic strictures.

Resection of the strictures and primary anastomosis were done in $39(42.9 \%)$ patients while substitution urethroplasty (augmentation and replacement with penile or scrotal skin or buccal mucosa) was performed in $48(52.7 \%)$ patients (Table 4). All the patients had sterile urine on culture before the procedure. General anaesthesia was used in $9(9.9 \%)$ patients 5 of which had buccal mucosal graft. The rest were done with spinal anesthesia. The mean duration of surgery was $98.25 \pm 17.8$ minutes (range 60-120) for resection and en-to-end anastomosis, while substitution urethroplasty took a little longer, with a mean operation time of $125.4 \pm$ 23.4 minutes.

The postoperative complications (Table 5) included urethral fistula in $6(6.6 \%)$ patients, out of which $4(66.7 \%)$
TABle 1: Age distribution of patients.

\begin{tabular}{lcc}
\hline Age (years) & Frequency & Percentage \\
\hline$<10$ & 2 & 2.2 \\
$11-20$ & 4 & 4.4 \\
$21-30$ & 18 & 19.8 \\
$31-40$ & 17 & 18.7 \\
$41-50$ & 20 & 21.9 \\
$51-60$ & 13 & 14.3 \\
$61-70$ & 13 & 14.3 \\
$71-80$ & 4 & 4.4 \\
\hline Total & 91 & 100 \\
\hline
\end{tabular}

TABLE 2: Aetiology of strictures in 91 patients.

\begin{tabular}{lcc}
\hline Aetiology & Frequency & Percentage \\
\hline Postinfective & 53 & 58.2 \\
Posttraumatic & 30 & 32.9 \\
Iatrogenic & 5 & 5.5 \\
Postprostatectomy & 3 & 3.3 \\
\hline Total & 91 & 100 \\
\hline
\end{tabular}

TABLE 3: Site and aetiology of urethral stricture in 91 patients.

\begin{tabular}{lcccc}
\hline \multirow{2}{*}{ Aetiology } & \multicolumn{4}{c}{ Site } \\
& Posterior & Bulbar & Bulbo-penile & Penile \\
\hline Postinfective & - & 17 & 29 & 5 \\
Posttraumatic & 18 & 7 & 4 & 1 \\
Iatrogenic & 5 & 2 & 1 & 1 \\
Postprostatectomy & 3 & - & - & - \\
\hline Total & 26 & 26 & 34 & 7 \\
\hline
\end{tabular}

TABLE 4: Operative procedures.

\begin{tabular}{lcccc}
\hline $\begin{array}{l}\text { Type of } \\
\text { urethroplasty }\end{array}$ & $\begin{array}{c}\text { Penile } \\
\text { (skin) }\end{array}$ & $\begin{array}{c}\text { Scrotal } \\
(\text { skin })\end{array}$ & Others & Total (\%) \\
\hline $\begin{array}{l}\text { Resection and } \\
\text { anastomosis }\end{array}$ & - & - & - & $39(42.9)$ \\
$\begin{array}{l}\text { Augmentation } \\
\quad \text { Flap }\end{array}$ & 23 & 6 & - & $29(31.9)$ \\
$\quad$ Graft & 1 & - & 5 & $6(6.6)$ \\
$\begin{array}{l}\text { Substitution } \\
\quad \text { Flap }\end{array}$ & 16 & 1 & - & $17(18.7)$ \\
\hline Total & 40 & 7 & 5 & $91(100)$ \\
\hline
\end{tabular}

Key: others: buccal mucosal graft.

had flap augmentation and 2 had tabularized pedicled penile skin flap. None of the resection and end-to-end anastomosis patients had fistula formation. Wound infection was seen in $18(19.8 \%)$ patients, made up of $15(83.3 \%)$ that had substitution urethroplasty (augmentation 9, and replacement 6$)$ and $3(16.7 \%)$ that had resection and anastomosis. Restricture was seen in $12(13.2 \%)$ patients, of which $7(58.3 \%)$ had resection and anastomosis and $5(41.7 \%)$ 
TABle 5: Postoperative complications.

\begin{tabular}{lccc}
\hline Complications & $\begin{array}{c}\text { Resection and } \\
\text { anastomosis } \\
(\%)\end{array}$ & $\begin{array}{c}\text { Augmentation } \\
(\%)\end{array}$ & $\begin{array}{c}\text { Substitution } \\
(\%)\end{array}$ \\
\hline $\begin{array}{l}\text { Wound } \\
\text { infection }\end{array}$ & 3 & 9 & 6 \\
$\begin{array}{l}\text { Restricture } \\
\text { Fistula }\end{array}$ & 7 & 4 & 3 \\
Total & - & 13 & 2 \\
\hline
\end{tabular}

had substitution urethroplasty. Four fistulae healed spontaneously on suprapubic cystostomy drainage, while 2 were repaired. Majority of the patients, 67 (73.6\%), did not have any postoperative complications.

Seventy-seven $(84.6 \%)$ of the patients had satisfactory voiding at discharge with a urinary flow rate of at least 10 $15 \mathrm{mls} / \mathrm{sec}$, and eleven (12.1\%) patients had maximal flow rate of over $15 \mathrm{mls} / \mathrm{sec}$ on discharge. The mean follow-up duration was 3 months, and majority of the patients were lost to followup after 6 months.

\section{Discussion}

Urethral stricture disease has been a common urological problem in the West African subregion from time immemorial. The vast majority of urethral strictures in this part of the world present late with many complications, and this may be because of the social stigma associated with genital problems. Urethral stricture disease affects all age groups but is most common in males in their prime of life with mean age ranging between 30 and 50 years [5-7].

In the past, post-infective urethral strictures especially following gonococcal urethritis predominated [7]; however, there is now a changing pattern of aetiology with trauma accounting for most cases $[8,9]$. In this study, postinfective strictures were still more common in variance with what is obtainable in other parts of Nigeria [10]. This may be due to higher urbanization in those parts of the country leading to more automobile accidents and other forms of trauma. Other causes of urethral stricture of particular interest include posturethral catheterization and postprostatectomy $[11,12]$. In this study there were 3 cases of urethral strictures following traumatic catheterization and another 3 following prostatectomy. One of the postprostatectomy strictures in this series were managed by serial dilatation, anastomotic urethroplasty and flap augmentation. This is in contrast to Onuigbo et al's [11] experience where all their patients were managed by serial dilatation with good results. The choice of modality of treatment depends on extent of fibrosis, site, and length of the stricture.

In the management of anterior urethral strictures, resection with spatulation, followed by mucosa to mucosa tension-free end to end anastomosis of the urethra, was the most frequently performed procedure in our series because most of the strictures were short segment, solitary, and located in the anterior urethra. Such alignment of the urethra is responsible for the high success rate of anastomotic urethroplasty, which is in excess of $90 \%$ and sustained on long-term basis $[13,14]$. Patients with complicated strictures for example, urethro-cutaneous fistulae, extensive periurethral fibrosis, false passages from previous attempts at dilatation, diverticuli, and others, require more robust surgical technique which entails maximal excision of scar tissue with conservation of the ischiocavernosus and bulbospongiosus muscles responsible for ejaculation at the same time dissecting in the mid-line to protect the nervi erigentis proximally particularly at the bulbomembranous urethra. This group of patients requires substitution urethroplasty by way of augmentation or total replacement of the diseased segment. The success rate of these surgeries is measured by increase in urine flow rate and patients satisfaction. The success rate has been variously reported to range between 40 to $80 \%$. In this study 77 (84.6\%) had satisfactory voiding as indicated by urine flow rate of $10-15 \mathrm{~mL} / \mathrm{s}$; however, it was difficult to assess the long-term impact of substitution urethroplasty on voiding because of poor followup. Most of the patients were lost to followup by the first 6th postoperative month.

The postoperative complications are similar to earlier reports, with wound infection being the most common. Restricture is common in patients that had resection, and end-to-end anastomosis and fistulae are mostly seen after substitution urethroplasty with most closing spontaneously.

\section{Conclusion}

Urethral stricture disease is a common problem in northeastern Nigeria with the infective causes still predominating in some areas although traumatic causes are on the rise. One-stage urethroplasty is most appropriate with acceptable outcome in our environment considering our prevailing social and economic factors.

\section{References}

[1] C. A. Attah, O. Mbonu, and R. M. Anikwe, "Treatment of urethral strictures in University of Nigeria Teaching Hospital," Urology, vol. 20, no. 5, pp. 491-494, 1982.

[2] B. Fall, Y. Sow, I. Mansouri et al., "Etiology and current clinical characteristics of male urethral stricture disease: experience from a public teaching hospital in Senegal," International Urology and Nephrology, vol. 43, no. 4, pp. 969-974, 2011.

[3] M. R. Cooperberg, J. W. McAninch, N. F. Alsikafi, and S. P. Elliott, "Urethral reconstruction for traumatic posterior urethral disruption: outcomes of a 25-year experience," Journal of Urology, vol. 178, no. 5, pp. 2006-2010, 2007.

[4] J. T. Anger, N. D. Sherman, E. Dielubanza, and G. D. Webster, "Erectile function after posterior urethroplasty for pelvic fracture-urethral distraction defect injuries," BJU International, vol. 104, no. 8, pp. 1126-1129, 2009.

[5] A. E. Aghaji and C. A. Odoemene, "One-stage urethroplasty for strictures: Nigerian experience," International Journal of Urology, vol. 8, no. 7, pp. 380-385, 2001.

[6] N. K. Dakum, V. M. Ramyil, and C. O. Amu, "Outcome of urethroplasty for urethral stricture at jos universitry teaching hospital," Nigerian Journal of Clinical Practice, vol. 11, no. 4, pp. 300-304, 2008. 
[7] A. Ahmed and G. D. Kalayi, "Urethral stricture at Ahmadu Bello University Teaching Hospital, Zaria,” East African Medical Journal, vol. 75, no. 10, pp. 582-585, 1998.

[8] K. H. Tijani, A. A. Adesanya, and C. N. Ogo, "The new pattern of urethral stricture disease in Lagos, Nigeria," The Nigerian postgraduate medical journal, vol. 16, no. 2, pp. 162-165, 2009.

[9] R. Mathur, G. Aggarwal, B. Satsangi, F. Khan, and S. Odiya, "Prognosis of urethral strictures following pelvic fracture urethral distraction defects-A single centre study," International Journal of Surgery, 2010.

[10] T. C. Oguike, V. C. Onuora, and E. Obarisiagbon, "The changing pattern of urethral stricture disease in Midwestern Nigeria," Journal of Medicine and Biomedical Research, vol. 5, no. 2, pp. 50-54, 2006.

[11] W. Onuigbo and G Njeze, "Postprostatectomy urethral stricture in elderly Nigerians," WebmedCentral Urology, vol. 1, no. 9, Article ID WMC00836, 2010.

[12] S. Prabhu, W. Cochran, P. A. M. Raine, and A. F. Azmy, "Postcatheterization urethral strictures following cardiac surgery in children," Journal of Pediatric Surgery, vol. 20, no. 1, pp. 69-71, 1985.

[13] R. A. Santucci, L. A. Mario, and J. W. McAninch, "Anastomotic urethroplasty for bulbar urethral stricture: analysis of 168 patients," Journal of Urology, vol. 167, no. 4 I, pp. 1715-1719, 2002.

[14] R. Turner-Warwick, "Urethral stricture surgery," in Current Operative Surgery-Urology, A. R. Mundy, Ed., pp. 160-218, Balliere Tindall, London, UK, 1988. 


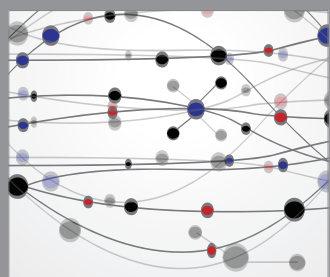

The Scientific World Journal
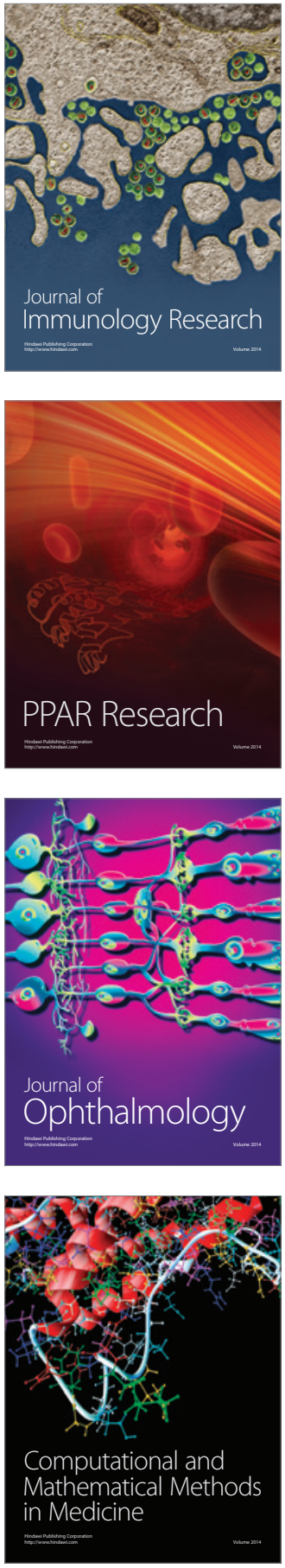

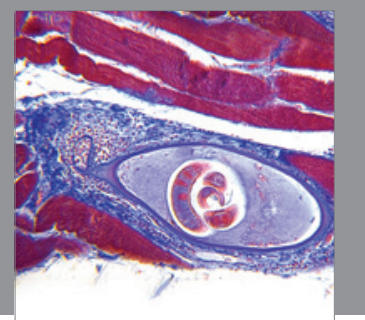

Gastroenterology

Research and Practice
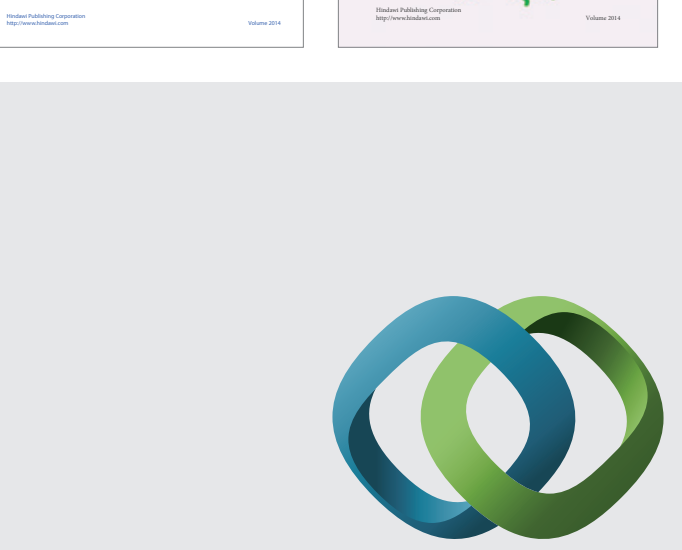

\section{Hindawi}

Submit your manuscripts at

http://www.hindawi.com
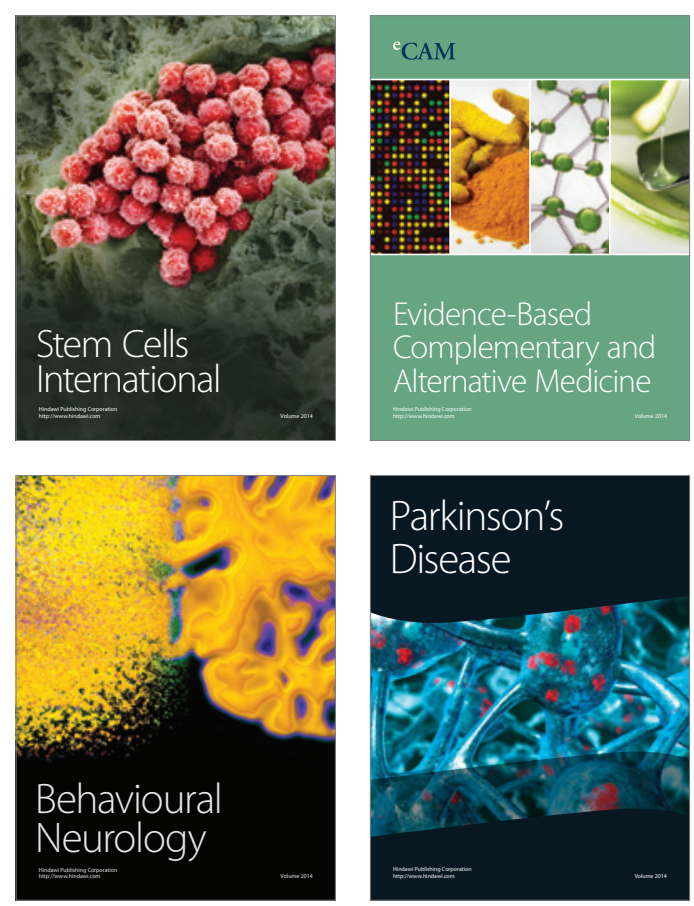

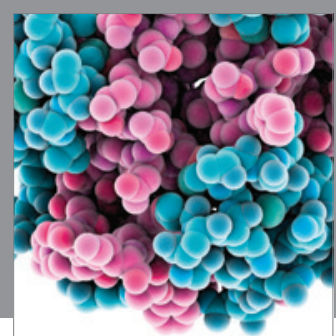

Journal of
Diabetes Research

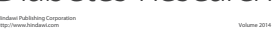

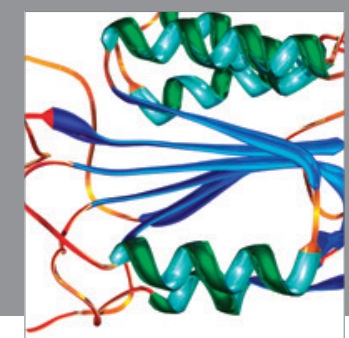

Disease Markers
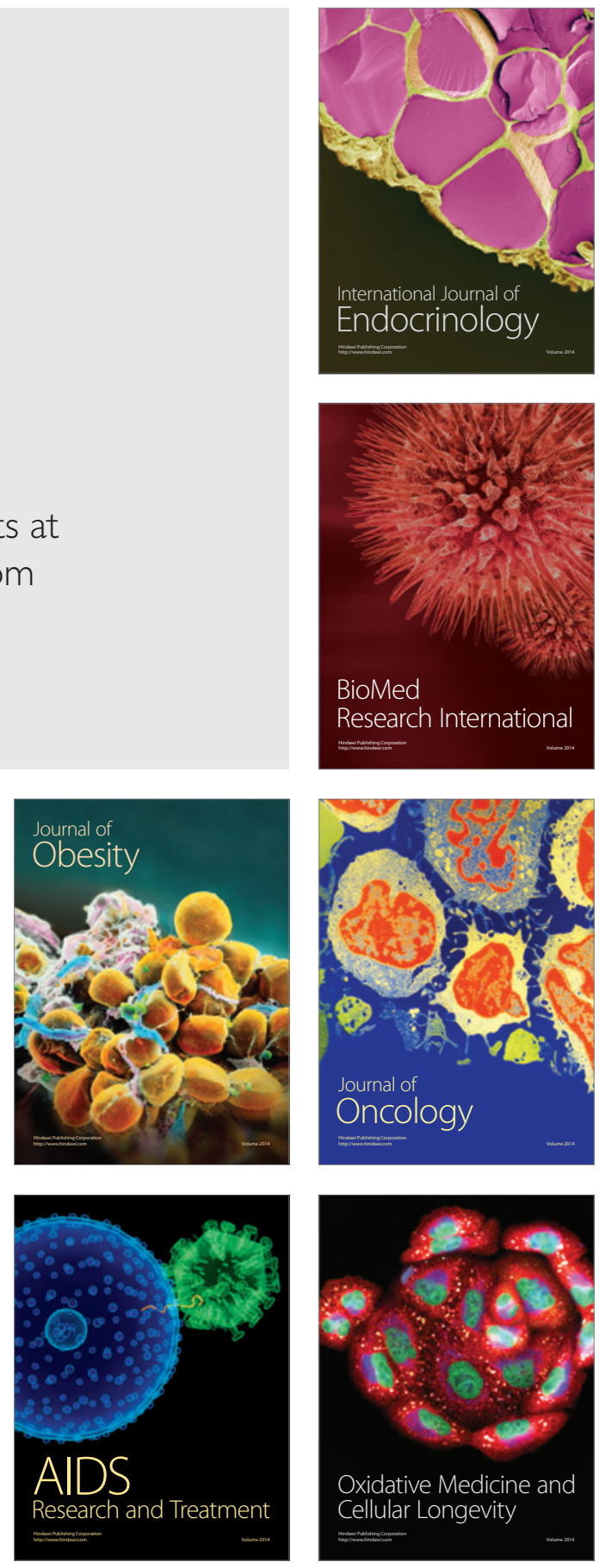